\title{
Theoretical Insights on Integrated Reporting: Valuing the Financial, Social and Sustainability Disclosures
}

\section{Mark Anthony Camilleri ${ }^{12}$ (Ph.D. University of Edinburgh)}

This is a pre-publication version.

How to Cite: Camilleri, M.A. (2019). Theoretical Insights on Integrated Reporting: Valuing the Financial, Social and Sustainability Disclosures. In: Idowu S., Del Baldo M. (eds) Integrated Reporting. CSR, Sustainability, Ethics \& Governance. Cham, Switzerland, Springer Nature. DOI: https://doi.org/10.1007/978-3-030-01719$4 \_3$

\begin{abstract}
Organisations are increasingly disclosing financial and non-financial performance as they are becoming more accountable and transparent to the providers of capital and other interested parties. Most of them are clearly specifying their environmental, social and governance (ESG) content, materiality and assurance mechanisms in their corporate disclosures. Very often, the organisations integrate financial, social and sustainability reporting. In this light, this chapter provides a critical review of key theoretical underpinnings that have anticipated the development of the corporations' integrated disclosures. Afterwards, it describes the International Integrated Reporting Council's $<\mathrm{IR}>$ Framework and its guiding principles. This contribution posits that there are potential tensions and challenges for those organisations who intend using the $<\mathrm{IR}>$ Framework. In conclusion, this chapter outlines future avenues as it identifies knowledge gaps in the realms of integrated reporting.
\end{abstract}

Keywords: Integrated Reporting, IR, Financial Reporting, Non-Financial Reporting, Corporate Social Responsibility, CSR, CSR Reporting, Integrated Disclosures.

\footnotetext{
${ }^{1}$ Department of Corporate Communication, Faculty of Media and Knowledge Sciences, University of Malta, Msida, MDS2080, MALTA. Email: mark.a.camilleri@um.edu.mt

${ }^{2}$ The Business School, University of Edinburgh, Bucchleuch Place, Edinburgh, EH8 9JS, SCOTLAND.
} 


\section{Introduction}

Academic research is proliferating on the documentation and analysis of non-financial reporting. Many studies are clearly indicating how non-financial reporting and disclosures relating to environmental, social and governance (ESG) performance are increasingly becoming the norm for global multinational corporations (Ioannou \& Serafeim, 2016; Camilleri, 2015a,b; Idowu, Capaldi, \& Zu, 2013; Aerts \& Cormier, 2009). The corporate financial reporting consists of backward-looking financial information (Beck, Dumay \& Frost, 2017; Camilleri, 2017; Crowther, 2016). However, such reported content may not necessarily reveal the whole picture of the organisations' performance (Burritt \& Schaltegger, 2010). This issue has inevitably led to the development of the integrated reporting guidelines (Adams \& Frost, 2008; Bhimani \& Langfield-Smith, 2007). Hedberg \& Von Malmborg (2003) reported that there were companies who were already using the GRI guidelines to enhance their visibility and control of their triple bottom line at the corporate level. Subsequently, IIRC has recently formalised its guidelines on financial and non-financial disclosures. Its International Framework for Integrated Reporting $<\mathrm{IR}>$ has been promoted as a solution to the shortcomings in corporate financial reporting (Dumay, Bernardi, Guthrie \& Demartini, 2016; Cheng, Green, Conradie, Konishi \& Romi, 2014; IIRC, 2013). Hence, integrated reporting sought to offer a broad picture of the modern organisations by shifting away from stand-alone financial statements, sustainability or social responsibility reports, towards a document that communicated a holistic picture of their value creating activities.

Gone are the days where financial performance could be considered as the only measure of a company's worth. With a wide plethora of possible disclosure formats, the integrated reports have bridged the gap by including non-financial information that is relevant to communicating corporate strategy. $<\mathrm{IR}>$ combines financial and non-financial disclosures of the organisations' 
performance in one statement. Therefore, <IR>'s 'integrated thinking' stimulates the businesses and other entities to think about how they could generate value for themselves and for society. The purpose of this framework is to raise awareness on guiding principles and relevant content that could be featured in corporate reports, and to explain the fundamental concepts that underpin them (Dumay, Bernardi, Guthrie \& Demartini, 2016). Additionally, the adoption of $<\mathrm{IR}>$ is further expected to tackle a number of problems that were (and are still) evident in conventional, stand-alone sustainability reports, such as; the failure to account for all sources of value creation, the complex interconnections between sustainability and financial performance, and the communication of a company's business model (Eccles \& Krzus, 2010; Eccles, Serafeim \& Krzus, 2011).

As integrated reporting focuses on long-term performance from various perspectives; it offers a great opportunity for companies to instill greater confidence among stakeholders as they become more accountable and transparent (Stacchezzini, Melloni \& Lai, 2016; Lozano \& Huisingh, 2011). $<$ IR $>$ commends that its integrated reports ought to be concise, reliable and complete, in all material matters, both positive and negative, in a balanced way and without error or bias. $<\mathrm{IR}>$ 's online site provides links to exemplary organisations who are already using its guiding framework (IR, 2017). The ease of access to IIRC's public data provides scholars with greater knowledge and understanding of the benefits and costs that are associated with the $<\mathrm{IR}>$ Framework. Hence, the future development of $<\mathrm{IR}>$ should be informed by stakeholder engagement with practitioners and a systematic, rigorous research approach that gathers experts' opinions on the implications for standard setting bodies, report preparers and their users.

This chapter addresses a research gap in academia along two lines of investigation. Firstly, it examines the International Integrated Reporting Council's $<\mathrm{IR}>$ guiding principles and content 
elements. Secondly, it links $<\mathrm{IR}>$ with key theoretical underpinnings. The author suggests that the agency, stewardship and institutional theories have contributed to the development of the $<$ IR $>$ field (Ioannou \& Serafeim, 2012; Brammer, Jackson \& Matten, 2012; Muth \& Donaldson, 1998; Davis, Schoorman \& Donaldson, 1997; Scott, 1995; Ness \& Mirza, 1991; DiMaggio \& Powell, 1991; Eisenhardt, 1989). Indeed, prior research has used legitimacy theory (Beck et al., 2015; Deegan, 2002; Suchman, 1995) to interpret corporate reporting practices, but it had also focused on disclosure content as it considered the perceived users of corporate reports. Thus, this chapter adds value to the extant literature by exploring the emergence of non-financial reporting within a broader legitimation strategy (Idowu, et al., 2013). The author contends that the concepts of isomorphism (Dacin, 1997; Deephouse, 1996) and isopraxism (Adams Potter, Singh \& York, 2016) elucidate our interpretation on why corporate reporting approaches are (or are not) converging toward integrated reporting.

The rationale for this contribution is to better understand how the $<\mathrm{IR}>$ framework improves the transparency and accountability of financial, social and sustainability disclosures. This research explores the theoretical insights from social sciences and links key conceptual developments with the integrated reporting of financial and non-financial disclosures. This study critically appraises <IR>'s framework and discusses about its potential pitfalls and challenges.

\section{The Conceptual Developments: Paving the way for Integrated Reporting}

The $<\mathrm{IR}>$ Framework's broader view of value creation and its multiple capital concept calls for an enhanced stewardship of the organisations' capitals; whilst promoting a better understanding of the interdependencies between the capitals (IIRC, 2013, p.8). Relevant theoretical perspectives as well as sound empirical research suggest that the practicing organisations' underlying motive behind their non-financial disclosures is to maximise their 
financial capital and profit. This argumentation is synonymous with many conceptual theories in academic literature that seek to justify the rationale for voluntary, integrated reporting (Adams et al., 2016; Idowu et al., 2013; Deegan, 2002, Suchman, 1995; Scott, 1995; Eisenhardt, 1989):

\subsection{The Agency Theory}

In the twentieth century, corporations were clearly distinguishing the difference between ownership and control of wealth. The business owners were considered as principals as they employed executives (agents) to manage their firms. The latter executives acted as agents for the principals, and they were morally responsible to maximise their shareholders' wealth (i.e. the prinicipals' wealth). The executives have accepted their agents' status because they perceived the opportunity to maximise their own utility. The agency theory suggests that the company executives and their principals are motivated by opportunities for their own personal gain (Eisenhardt, 1989). Rightly so, the principals may invest their wealth in profitable companies and design governance systems in ways that maximise their investments. On the other hand, agents accept the responsibility of managing their principals' undertakings to secure their employment prospects.

However, at times, there may be interest divergence between the managers and their principals. There may be situations where the agents may feel constrained by their principals' imposed structures and controlling mechanisms (Davis et al., 1997). This matter could lead to unproductivity outcomes and will ultimately bring significant losses to the principals themselves. In the event where the agent would have no discretion at all, the firm would be owner-managed. In this case, having a situation where principals are autocratic towards their agents could result in serious repercussions for the businesses' prospects. The crux of the agency theory is that principals are expected to delegate authority to agents to act on their 
behalf (Ness \& Mirza, 1991). It is this delegation that at times allows agents to opportunistically build their own utility at the expense of the principals' utility. This happens when there are unaligned objectives; where managers may be motivated by their individualistic, self-serving goals, rather than being stewards for their principals (Eisenhardt, 1989).

\subsection{The Stewardship Theory}

The stewardship theory is the collective-serving model of behaviour that is driven by the organisations' intrinsic values and a genuine desire to do what is best for society and the planet (Donaldson \& Davis, 1991). The stewardship behaviours benefit principals through the positive effects of profits on corporate dividends and share prices. Consequently, the stewards place higher value on cooperation than defection (these terms are also found in the game theory), because they perceive greater utility in cooperative behaviours. Stewardship theorists assume that there is a strong relationship between successful organisations and their principals' satisfaction. The stewards protect and maximise their shareholders' wealth because by so doing, they maximize their utility functions toward principals.

Stewards who successfully improve their organisational performance will also satisfy other stakeholder groups who have their own vested interests. Therefore, pro-organisational stewards are motivated to maximise organisational performance, whilst satisfying the competing interests of shareholders. The utility that they gain from pro-organisational behaviours is higher than the utility that could be gained through individualistic, self-serving behaviours. This theory suggests that stewards believe that their interests are aligned with those of the corporation that engaged them (Muth \& Donaldson, 1998). Ideally, the stewards ought to be committed to improve their organisational performance rather than satisfying their personal motivations. This theory's ideals are closely aligned with $<$ IR $>$ 's principles for value creation.

IIRC's <IR > Framework emphasises the stewardship of multiple capitals, including; financial, 
manufactured, intellectual, human, social and natural capital. In the past, the accountability of social and environmental capitals has often been found to be completely lacking in financial reporting (Adams et al., 2016; Muth \& Donaldson, 1998). In addition, some anecdotal evidence suggests that companies are not always presenting a true and fair view of their negative impacts. On the other hand, there are other organisations who may be reluctant to promote their responsible and sustainable behaviours. This may be due to a lack of awareness on the business case for such activities. The motivations for undertaking stewardship behaviours, including; material ESG initiatives (that may be reported within integrated reports) seem to fall into two increasingly converging camps: doing good practices (this is consistent with the predictions of the stewardship theory) or doing well (this is consistent with both institutional and legitimacy theories).

\subsection{The Institutional Theory}

Different components of the institutional theory explain how certain processes become established as authoritative guidelines for societal behaviours. Very often, structures and institutions are created, diffused, adopted, and adapted over space and time; and eventually they may also fall into decline and disuse. Unlike the efficiency-based theories which focus on profit maximisation or on the interactions between markets and governments, the institutional theory considers a wider range of variables that could influence the decision-making processes in organisations.

This theory clarifies how firms respond to their institutional environments in which they operate. Stakeholders, including; governments, regulatory authorities, non-governmental organisations (NGOs), and organisations within the supply chain can exert their influence on any business. Scott (1995) held that, in order to survive, organisations must conform to norms and rules that are prevailing in their operating environment. Their compliance with the 
institutions' formal regulations and ethos will earn them legitimacy among stakeholders (Beck et al., 2015; Dacin, 1997; Deephouse, 1996; Suchman, 1995). The institutional theory's applications have expanded even further; as more research is showing how the institutions effect organisational behaviours, particularly on CSR issues. Historically, the notion of CSR has emerged from the institutionalised forms of social solidarity from liberal market economies. The institutional theory offers promising ways of investigating what lies at the heart of the publics' concern. Therefore, corporations may be influenced by the institutions' voluntary principles, policies and programmes. Their responsible behaviours have often been triggered by socio-political forces and pressure groups. In this case, CSR practice rests on the dichotomy between the corporations' voluntary engagement and their socially binding responsibilities (Brammer et al., 2012). The fact that CSR is 'voluntary' is a clear reflection of the practicing organisations' institutional context. Alternatively, CSR may be driven by legal, customary, religious or other defined institutions.

Undoubtedly, numerous institutions have played a dynamic role, both individually and collectively in the development of integrated reporting. While governments have been the primary force for the promotion of financial reporting standards through security exchange commissions; other institutions like IIRC or GRI have facilitated the growth and diffusion of ESG reporting among practicing organisations. For the time being, it may appear that there is a demand for CSR reporting mechanisms by marketplace stakeholders. For this reason, corporations are communicating their ESG credentials (Camilleri, 2015a). This way, they are accountable and transparent about their modus operandi with regulators, industry, and stakeholder groups. Moreover, the corporations' continuous engagement with external institutions, particularly multi-governmental organisations, social and environmental NGOs as well as the standard-setting organisations have brought valuable principles and guidelines in the realms of sustainability reporting (Camilleri, 2015a). 
Isomorphism has been constructed in conjunction with the applications of the institutional theory (Erlingsdottir \& Lindberg 2005; Dacin, 1997; DiMaggio \& Powell, 1991). This concept has largely been propagated through global cultural and associational processes. Isomorphic developments arise when ideas or innovations travel and are adopted in different contexts (Harding, 2012; Dacin, 1997; Deephouse, 1996). For instance, despite all possible configurations of local economic forces, power relationships, and forms of traditional culture it might consist of, a previously-isolated island society that has made contact with the rest of the globe would quickly take on standardised forms that are similar to a hundred other nationstates around the world (Meyer, Boli, Thomas \& Ramirez, 1997). Similarly, the notion of isopraxism refers to ideas that are translated and modified by different actors to suit their own needs.

Isomorphism and its related notion, isopraxism are potentially helpful for framing our interpretation of why corporate reporting approaches may converge (or not) over time. For example, the principles-based and non-mandatory $<\mathrm{IR}>$ Framework could potentially create explicit and implicit reporting norms that shape the non-financial information of organisations that ought to be communicated through their integrated reporting. In this sense, isomorphism may be useful to understand how and why the disclosures of ESG content can become widely accepted across companies, over time (Adams et al., 2016; Deephouse, 1996). In a similar vein, isopraxism has been used to describe instances where identifiable institutional forces lead to new and different actions within specific organisational and social instances. Therefore, isopraxism suggests that organisations may be intrigued to move toward more integrated approaches to reporting. At times, legitimate organisations may be willing to voluntarily disclose their adapted ESG reports, out of their own volition. However, they may not necessarily label them 'integrated', or join the IIRC's <IR $>$ Framework (Erlingsdottir \& Lindberg 2005; Harding 2012). 


\subsection{The Legitimacy Theory}

Very often, the institutional environments provide regulatory frameworks and may be considered as a considerable breath of narratives pertaining to non-financial disclosures, in different jurisdictions. Hence, there is a possibility that responsible organisations will become legitimate if they comply with relevant societal rules that are found in the countries where they operate (Beck et al., 2015; Deegan, 2002). The stakeholders perceive that organisations are legitimate when "their actions are desirable, proper, or appropriate within some sociallyconstructed system of norms, values, beliefs, and definitions" (Suchman, 1995, p. 574). This conception suggests that the role of the legitimacy theory is to justify the organisations' behaviour, particularly when they implement and develop social and environmental initiatives. It goes without saying that the stakeholders will recognise those legitimate organisations that are upholding their social contract in accordance with the expectations of society. Therefore, the drivers of institutional legitimacy may be influenced by the organisations' external environment; according to the culturally-defined values and beliefs. On the other hand, stakeholders will severely sanction irresponsible organisations when they do not respect social norms and ethical values.

Suchman (1995) described legitimacy as an operational resource assuming a "high level of managerial control over legitimating processes" (p. 576). Others suggested that legitimacy is strategic as it emanates from recurring conflicts between management and stakeholders (Dacin, Oliver \& Roy, 2007; Suchman 1995). Organisational legitimacy could be achieved by forging strong relationships with external stakeholders (Camilleri, 2017). For this reason, organisations may decide to change and adapt their corporate disclosures according to their stakeholders' expectations to achieve legitimacy. On the other hand, changes in disclosure patterns may be driven by internal decisions on materiality. Corporate reporting could be considered as a 
mitigating factor that is driven from inside the organisation (Campbell \& Beck, 2004). Therefore, the managers' agenda is to strategically enhance their legitimacy through stakeholder engagement. They may also make financial and ESG disclosures widely available to interested parties to achieve legitimation. This position is consistent with <IR >'s framework. Within this context, the $<\mathrm{IR}>$ framework provides significant support to organisations who are willing to disclose their non-financial reports. However, when organisations utilise IIRC's framework for their very first time, they may inevitably have to adapt their financial and ESG reports as per $<\mathrm{IR}>$ 's recommended framework. Hence, $<\mathrm{IR}>$ 's reporting guidelines provide a passive avenue for institutional legitimisation. It is through the development of such guiding principles that society and external stakeholders are continuously influencing organisations to restore their ethical and social disclosures (Campbell \& Beck, 2004).

The conditions for legitimacy are often constructed by responsible organisational behaviours. For example, relevant research on the legitimacy theory reported that there were organisations who were voluntarily disclosing their non-financial reports. Companies were seeking external legitimation by reporting their environmental performance (Brown \& Deegan, 1998). Other corporations who decided to follow GRI's reporting guidelines or resorted to the <IR>'s framework were increasingly aligning their internal reflections with external outputs (Beck et al., 2015). Initially, the rationale behind their integrated reporting was to improve their organisations' external legitimation among stakeholders. However, at a later stage they realised that their external reports were informed by their organisation's strategic positioning, and not constrained by the promulgation of the voluntary guidelines (Beck et al., 2015). Evidently, more organisations are conforming to the prevailing definitions of legitimacy through their disclosures of responsible and sustainable actions. Consequently, these responsible organisations' leadership sets the agenda for stakeholder engagement and ESG reporting. The 
underlying objective is to build or enhance reputation (Aerts \& Cormier, 2009) that will positively impact on the organisations' capital flows.

\section{An Appraisal of Integrated Reporting}

In the aftermath of the global economic and financial crisis of 2007-2008, many policy makers, regulatory authorities and leading financial institutions were striving in their endeavours to improve their corporate reporting mechanisms (Crowther, 2016). At the time, there was an increased awareness on how ESG issues could help to improve corporate reputation and economic value (Camilleri, 2017). The ethical behaviours in financial reporting is often equated with the obligation of companies to disclose a true and fair view of their organisational performance (Maniora, 2015; Simnett \& Huggins, 2015). Organisations are accountable and transparent to their stakeholders when they report their financial as well as non-financial information to their stakeholders. PWC (2015) also suggested that CEOs believed that measuring and reporting total non-financial impacts contributes to long term success. Although, historical financial statements are essential in corporate reporting, particularly for compliance purposes, their disclosures do not always provide meaningful information regarding business value (ACCA, 2016). Therefore, the communication on value creation should be the next step in the evolution of corporate reporting. The $<\mathrm{IR}>$ framework is one of the internationally-accepted frameworks that provides guidance on the reporting of financial information and ESG issues and on how their integrated reporting may lead to the creation of value over the short, medium and long term (IR, 2017; de Villiers, Rinaldi \& Unerman, 2014; Adams \& Simnett, 2011; Adams \& Larrinaga-González, 2007). The council has promoted the concept of integrated thinking and reporting as its $<\mathrm{IR}>$ framework includes metrics with the aim of communicating all activities and outputs that could potentially create value to the 
organisations' capitals. The $<\mathrm{IR}>$ Framework categorises different stocks of value, including; Financial Capital; Manufactured Capital; Intellectual Capital; Human Capital; Social (and Relationship) Capital; as well as Natural Capital. IIRC has aligned these capital allocations and corporate behaviours with its wider goals of financial stability and sustainable development.

Whilst the end of year financial statements focuses on financial capital, IIRC (2013) has paved the way for the next generation of annual reports that enable stakeholders to make a more informed assessment of the organisation's strategy, governance, performance and prospects. The $<$ IR $>$ Framework relies on resources - such as the expertise of people, intellectual property that was developed through research and development, and interactions with the environment and the societies in which they operate, along with its financial metrics. From this perspective, IIRC's guidelines were developed to address value creating activities that were missing from the corporations' disclosures. Hence, IIRC's (2013) <IR> framework established 'Guiding Principles' and 'Content Elements'. Its content is summarised in Table 1: 


\section{Table 1. A summary of the <IR $>$ Framework's Guiding Principles and Content Elements}

\section{Guiding Principles}

- Strategic focus and future orientation -gives an insight of the organisation's strategy;

- Connectivity of information - provides a holistic picture of the combination, interrelatedness and dependencies between the factors that affect the organisation's ability to create value over time;

- Stakeholder relationships - describes the nature and quality of the organisation's relationships with its key stakeholders;

- Materiality - discloses relevant information about matters that substantively affect the organisation's ability to create value over the short, medium and long term;

- Conciseness - provides sufficient context to understand the organisation's strategy, governance and prospects without being burdened by less relevant information;

- Reliability and completeness - includes all material matters, both positive and negative, in a balanced way and without material error;

- Consistency and comparability - ensures consistency over time and enabling comparisons with other organisations to the extent material to the organisation's own ability to create value.

\section{Content Elements}

- Organisational overview and external environment - What does the organisation do and what are the circumstances under which it operates?

- Governance - How does an organisation's governance structure support its ability to create value in the short, medium and long term?

- Business model - What is the organisation's business model?

- Risks and opportunities - What are the specific risk and opportunities that affect the organisation's ability to create value over the short, medium and long term, and how is the organisation dealing with them?

- Strategy and resource allocation - Where does the organisation want to go and how does it intend to get there?

- Performance - To what extent has the organisation achieved its strategic objectives for the period and what are its outcomes in terms of effects on the capitals?

- Outlook - What challenges and uncertainties is the organisation likely to encounter in pursuing its strategy, and what are the potential implications for its business model and future performance?

- Basis of preparation and presentation - How does the organization determine what matters to include in the integrated report and how are such matters quantified or evaluated?

(adapted from IIRC, 2013)

The 'Guiding Principles' underpin the preparation of an integrated report, whilst, the 'Content Elements' are the key categories of information that ought to be included in an integrated report (according to the $<\mathrm{IR}>$ Framework). There are no benchmarking on the above matters and the 
report is primarily aimed at the private sector; however $<\mathrm{IR}>$ could also be adapted to the public sector and to not-for-profit organisations. IIRC has set out a principle-based framework rather than specifying a detailed disclosure and measurement standard. This way each company sets out its own report rather than adopting a checklist approach. Hence, the report acts as a platform which explains what creates value to the business and how management protects this value. This gives the report more business impetus rather than mandating compliance-led approaches.

For the time being, the integrated reporting is not going to replace other forms of reporting but the vision is that large undertakings, including corporations, state-owned entities and government agencies, among others, may be expected to pull together relevant information to explain the key drivers of their non-financial performance. The disclosed information will only be included in the corporate report if it is material for the stakeholders. The term 'materiality' suggests that there are legal connotations that may be related to non-financial reporting. Yet, a few entities, out of their own volition, are already including ESG information in their integrated reports (Adams \& Larrinaga-González, 2007). In a nutshell, these organisations aim to provide a good insight into their resources, their relationships as they explain how they interact with their external environment to create value for themselves and toward society.

The development of the $<\mathrm{IR}>$ framework has brought significant improvements in terms of reporting and integration of financial and non-financial information. The IIRC has developed its very own $<\mathrm{IR}>$ framework following multi-stakeholder discussions with international financial accounting standard setters, institutional investors, providers of voluntary guidelines for corporate responsibility disclosures, the national accounting bodies and NGOs, among others. Therefore, IIRC represents key stakeholders that are poised to change the existing duality in corporate reporting of traditionally financial reports and discreet non-financial reporting. Initially, non-financial reporting was part of the Management Report and were filed 
within the corporations' annual reports. Back in the 1990s, there was the first spike of spurious social responsibility disclosures. Today, many companies are publishing their elaborated CSR Reports, Sustainability Reports, Corporate Citizenship Reports, Creating Shared Value Reports, and the like. These ESG reports have a lengthy tradition in voluntary reporting. The need for more comparable disclosures has led to the development of the reports which integrate financial and non-financial information (Adams et al., 2016; Adams, \& Frost, 2008). The scope of the integrated reporting is to provide a more holistic picture of an entity that encompasses financial and ESG information. IIRC created a globally accepted $<$ IR $>$ framework that elicits material information from organisations about their strategy, governance, performance and prospects in a clear, concise and comparable format. This framework has accelerated the evolution of integrated thinking in corporate reporting (Perego, Kennedy \& Whiteman, 2016). It has brought interesting developments in financial and ESG disclosures for the benefit of stakeholders, including institutional investors.

Yet, the reporting of non-financial performance remains voluntary. The reporting organisations are frequently providing an incomplete picture of their activities; even when they adopt nonfinancial guidelines (Adams et al., 2016). This implies that their reporting function ought to be subjected to external acceptance by an externally-recognised framework. It may appear that IIRC is still addressing this potential deficiency as it has provided a decent framework with clear definitions of target audiences, financial resource providers, et cetera (IIRC 2013, 2017). Arguably, it may appear that the standardisation of integrated reporting practices limits confusion as organisations disclose relevant and material information that is easily comparable to the other entities' disclosures. Perhaps, for the time being, the greatest challenge for report bearers is to identify which content should be incorporated within the integrated report. This is the reason why it is important to define the target groups of the report (Adams et al., 2016; 
Parent \& Deephouse 2007). Prospective non-financial reporting that is based on $<\mathrm{IR}>$ framework could provide a a single source document that gives a good snapshot of both financial and non-financial data. Debatably, while this framework is a significant development for the corporate disclosures of both financial and ESG matters, it has emerged following fruitful and collaborative debates among regulatory institutions, accounting bodies and interested parties.

\section{Potential Tensions for the Development of Integrated Reporting}

Many academic commentators have criticised the development of integrated reporting (Perego et al., 2016). Brown and Dillard (2014) argued that "IR remains an ideologically-closed approach that is more likely to reinforce rather than encourage critical reflection on 'business as usual' practices" (p. 1120). In a similar vein, Flower (2015) had voiced serious concerns about IIRC's approach to sustainability. The author held that the $<\mathrm{IR}>$ framework focuses on investors rather than stakeholders, society and the natural environment. These reproaches emphasise that there are some relevant critiques on integrated reporting. Moreover, the accountancy profession has undue power over the institutional processes that were expected to deliver a fundamental shift in framing corporate reporting and sustainability accounting practices (Crowther, 2016; Flower, 2015; Adams \& Larrinaga-González, 2007). For instance, Deegan (2007) maintained that environmental reporting is designed to repair organisational legitimacy. Whilst, Adams and Larrinaga-Gonzáles (2007) held that sustainability accounting is being carried out to conform with institutionalised norms. In a similar way, Hopwood (2009) pointed out that environmental accounting protected the firm's inner workings from external views. Thus, few papers have attempted to assess the consequences (costs and benefits) of integrated reporting (Stacchezzini et al., 2016; Stubbs \& Higgins, 2014; O’Dwyer, 2003). Previously, Neu, Warsame and Pedwell (1998) had admitted that environmental disclosures 
might advance the corporate image; in the absence of corresponding engagement. However, they also contended that socially responsible behaviours and their accounting are not necessarily concomitant. This issue could possibly limit the implementation of integrative reporting.

Stubbs and Higgins (2014) argued that the <IR $>$ framework focuses on the 'supply side', namely, the preparers of integrated reporting whilst leaving out the 'demand side', i.e. the users' perspectives on integrated reporting. These authors explored how Australian providers of financial capital were interpreting IIRC's $<$ IR $>$ framework. They concluded that there was a significant gap between the information that was supplied by reporting companies and information that was sought by the financial markets. The authors also claimed that IIRC's six capital model was not acknowledged by the Austalian investors. Similarly, Perego et al. (2016) hinted that the users of standalone sustainability reports were adjusting their bad ESG valuations to the level of integrated (financial and sustainability) report users. However, they also suggested that none of the standalone reports users were adjusting their valuations following the corporate disclosures about good ESG performance. They concluded that the report preparers made different value judgments when anchoring the effects of ESG information (Perego et al., 2016).

\section{Discussion and Conclusions}

In simple terms, an integrated report is a single report that combines the financial and nonfinancial disclosures. However, a thorough literature review suggests that the integrated report is more than just a summary of financial, social and sustainability information in corporate disclosures (Aluchna \& Idowu, 2017; Idowu et al., 2013). The integrated reports constitute a full picture of a company's overall business performance. Organisations are looking at all aspects of their value-creating capitals, including; financial; manufactured; intellectual; human; 
social (and relationship); as well as natural capitals (IR, 2013). These capitals complement and compete against each other. Therefore, the practitioners who would like to comply with IIRC's $<$ IR $>$ framework will probably experience a dynamic process of adaptation, learning and action to redesign their corporate reporting. They may have to change their internal management systems (Churet \& Eccles, 2014; Eccles \& Krzus, 2010), processes, strategies to incorporate ESG issues into their core business model.

Relevant academic literature has yielded many recommendations, ideas, concepts, and other types of inspiration that have surely improved corporate reporting (Crowther, 2016). This contribution reported how "integrated thinking" in corporate reporting involves the inclusion of material information on financial and non-financial matters (Adams \& Simnett, 2011). Moreover, the organisations' integrated reporting could be linked to the conceptual developments in the stewardship, institutional and legitimacy theories, among others. This chapter has indicated that these theoretical insights have focused on the rationale for the inclusion of non-financial information in corporate disclosures (Adams et al., 2016; Eccles \& Krzus, 2010). Although, there are reasonable arguments in favour and against integrated reporting; the researcher believes that the IIRC's <IR > framework has proved to be a useful instrument for many exemplary organisations who were recognised for their integrated reporting (IIRC, 2017). The $<$ IR $>$ framework contains guiding principles and content elements that will enable organisations to disclose a true and fair view of their holistic activities. Conversely, the avoidance of ESG disclosures from their corporate reports can result in a highly-distorted picture of current and future business activities (Camilleri, 2017).

This chapter has indicated how the theoretical insights from academic literature have led to the development of integrated reporting. It explained that the organisations' stewardship behaviours, including their 'integrated thinking' can help them improve their legitimacy among 
stakeholders and institutions. The researcher contended that IIRC's $<$ IR $>$ framework supports organisations in their holistic reporting approaches as it takes into account material information on financial, manufactured, intellectual, human, social and natural capitals.

\subsection{Implications for Practitioners}

Indeed, the IIRC's $<$ IR $>$ framework was a recent development in corporate reporting. This framework has its inherent limitations that were duly pointed out in this chapter. However this contribution maintains that integrated reporting provides a road map for those organisations who would like to pursue the sustainability path (Dacin et al., 2007). The $<$ IR $>$ framework is based on the general notion that integrated accounting considers both financial and nonfinancial information to give a true and fair view of the company's overall business performance. When practitioners embed ESG disclosures and "integrated thinking" they help to catalyse behavioural change in integrated reporting (Adams \& Simnett, 2011). This integrated thinking influences the practitioners' ethical behaviours and their stance on financial and non-financial performance (Camilleri, 2015b). The $<\mathrm{IR}>$ framework's strategic focus calls for both internalisation and externalisation processes. Internalisation is a process through which human resources adopt the $<\mathrm{IR}>$ framework's external ideas, opinions, views or concepts as their own. This process starts with learning what this guiding principle is all about and why its development makes sense to businesses themselves. The internal stakeholders will probably experience a process of adaptation until they finally accept that integrated reporting creates value over time. Thus, internalisation can be understood as a process of acceptance of a new set of norms and working practices.

In the context of integrated reporting, organisations' internal transformation leads to changes in terms of the embeddedness of ESG performance in their operational processes. The responsible organisations commit themselves to disclose externalities that affect stakeholders 
and other unrelated parties. In other words, through integrated reporting; the internal effects of integrated reporting are finally externalised outside the organisations' boundaries. At times, organisations may intentionally or unintentionally conceal ESG information from stakeholders. Certain unethical practices may result from conscious or unconscious organisational behaviours or simply from misconduct when dealing with extensive information outputs. In this light, $<\mathrm{IR}>$ framework is a step in the right direction as integrated reporting leads to the re-evaluation of corporate ethics (The IoDSA and the King Committee, 2009). This framework calls for sustainability accounting of ESG issues. Hence, the IIRC's $<$ IR $>$ framework could be considered as a driver for the creation of an ethically-minded corporate culture. Practicing organisations will therefore bind themselves to disclose material information about financial and ESG matters, both positive and negative that substantively affect their ability to create value over the short, medium and long term. They are also expected to provide sufficient context about their strategy, governance and prospects in a balanced way and without material error (Camilleri, 2017). The implementation of integrated reporting represents the companies' ethical obligation in their role of corporate citizens, as they provide a more holistic picture of the company's performance across departments (Eccles \& Krzus, 2010). Moreover, practitioners could ensure consistency over time as their integrated reporting could facilitate comparisons with other organisations.

\subsection{Future Research}

This chapter has addressed a gap in the literature as it linked relevant theoretical developments to better understand the rationale for integrated reporting in today's era. Academic literature has often relied on limited publicly available datasets on the diffusion of integrated reporting (Perego et al., 2016). Moreover, past contributions may have only focused on the 'supply side' pertaining to the $<\mathrm{IR}>$ framework; without investigating in much depth and breadth which 
organisational processes are crucial for integrated reporting (Simnett \& Huggins, 2015; de Villiers et al., 2014). It may appear that to date, there is still scant evidence about the strengths and weaknesses that are associated with the implementation of integrated reporting (Perego et al. 2016; Cheng et al., 2014). Therefore, empirical studies could explore how internal performance measurements and their disclosures may impact integrated reporting. Future qualitative research could identify which organisational processes and practices ought to be reported in integrated disclosures. Undoubtedly, there is potential for further studies that examine the content of integrated reports. Other research might investigate the usefulness of the organisations' integrated approaches to reporting financial and ESG information. In conclusion, the researcher posits that this construct is still emerging among academia; its conceptual development at this early stage is valuable because it exposes how the subject of financial, social and sustainability accounting is evolving among academia and practitioners.

\section{References}

ACCA (2016). Insights into Integrated Reporting. http://integratedreporting.org/wpcontent/uploads/2017/04/ACCAInsights_into_Integrated_Reporting.pdf_accessed 19 April, 2017

Adams, C. A. \& Larrinaga-González, C. (2007). Engaging with organisations in pursuit of improved sustainability accounting and performance. Accounting, Auditing \& Accountability Journal, 20(3), 333-355.

Adams, C. A. \& Frost, G. R. (2008). Integrating sustainability reporting into management practices. Accounting Forum. 32, (4), 288-302.

Adams, S., \& Simnett, R. (2011). Integrated Reporting: An opportunity for Australia's not-forprofit sector. Australian Accounting Review, 21(3), 292-301.

Adams CA, Potter B, Singh PJ and York J (2016). Exploring the implications of integrated reporting for social investment (disclosures) British Accounting Review, 48(3), 283-296.

Aerts, W., \& Cormier, D. (2009). Media legitimacy and corporate environmental communication. Accounting, organizations and society, 34(1), 1-27. 
Aluchna, M., \& Idowu, S. O. (2017). Responsible Corporate Governance: An Introduction. In Responsible Corporate Governance (pp. 1-7). Springer, Heidelberg, Germany.

Beck, C., Dumay, J., \& Frost, G. (2015). In pursuit of a 'single source of truth': from threatened legitimacy to integrated reporting. Journal of Business Ethics, 1-15.

Bhimani, A., \& Langfield-Smith, K. (2007). Structure, formality and the importance of financial and non-financial information in strategy development and implementation. Management Accounting Research, 18(1), 3-31.

Brammer, S., Jackson, G., \& Matten, D. (2012). Corporate social responsibility and institutional theory: New perspectives on private governance. Socio-economic review, 10(1), 3-28.

Brown, N., \& Deegan, C. (1998). The public disclosure of environmental performance information-a dual test of media agenda setting theory and legitimacy theory. Accounting and business research, 29(1), 21-41.

Brown, J., \& Dillard, J. (2014). Integrated reporting: On the need for broadening out and opening up. Accounting, Auditing \& Accountability Journal, 27(7), 1120-1156.

Burritt, R. L., \& Schaltegger, S. (2010). Sustainability accounting and reporting: fad or trend?. Accounting, Auditing \& Accountability Journal, 23(7), 829-846.

Camilleri, M. A. (2015a). Valuing stakeholder engagement and sustainability reporting. Corporate Reputation Review, 18(3), 210-222.

Camilleri, M. A. (2015b). Environmental, social and governance disclosures in Europe. Sustainability Accounting, Management and Policy Journal, 6(2), 224-242.

Camilleri, M. A. (2017). Corporate sustainability, social responsibility and environmental management: an introduction to theory and practice with case studies. Springer, Heidelberg, Germany.

Campbell, D., \& Cornelia Beck, A. (2004). Answering allegations: The use of the corporate website for restorative ethical and social disclosure. Business Ethics: A European Review, 13(2-3), 100-116.

Cheng, M., Green, W., Conradie, P., Konishi, N., \& Romi, A. (2014). The international integrated reporting framework: key issues and future research opportunities. Journal of International Financial Management \& Accounting, 25(1), 90-119.

Churet, C., \& Eccles, R. G. (2014). Integrated reporting, quality of management, and financial performance. Journal of Applied Corporate Finance, 26(1), 56-64.

Crowther, D. (2016). A social critique of corporate reporting: Semiotics and web-based integrated reporting. Routledge. Abington, Oxford, UK.

Dacin, M. T. (1997). Isomorphism in context: The power and prescription of institutional norms. Academy of management journal, 40(1), 46-81. 
Dacin, M. T., Oliver, C., \& Roy, J. P. (2007). The legitimacy of strategic alliances: An institutional perspective. Strategic Management Journal, 28(2), 169-187.

Davis, J. H., Schoorman, F. D., \& Donaldson, L. (1997). Toward a stewardship theory of management. Academy of Management review, 22(1), 20-47.

Deegan, C. (2002). Introduction: The legitimising effect of social and environmental disclosures-a theoretical foundation. Accounting, Auditing \& Accountability Journal, 15(3), 282-311.

Deegan, C 2007, 'Organisational legitimacy as a motive for sustainability reporting' in J. Unerman, J. Bebbington, B. O'Dwyer (ed.) Sustainability accounting and accountability, Routledge, London, United Kingdom, pp. 127-149.

Deephouse, D. L. (1996). Does isomorphism legitimate?. Academy of management journal, 39(4), 1024-1039.

de Villiers, C., Rinaldi, L., \& Unerman, J. (2014). Integrated Reporting: Insights, gaps and an agenda for future research. Accounting, Auditing \& Accountability Journal, 27(7), 1042-1067.

DiMaggio, P. J., \& Powell, W. W. (Eds.). (1991). The new institutionalism in organizational analysis (Vol. 17). Chicago, IL: University of Chicago Press.

Donaldson, L., \& Davis, J. H. (1991). Stewardship theory or agency theory: CEO governance and shareholder returns. Australian Journal of management, 16(1), 49-64.

Dumay, J., Bernardi, C., Guthrie, J., \& Demartini, P. (2016). Integrated reporting: a structured literature review. In Accounting Forum. 40(3), 166-185.

Eccles, R. G., \& Krzus, M. P. (2010). One report: Integrated reporting for a sustainable strategy. John Wiley \& Sons, Hoboken, New Jersey, USA.

Eccles, R. G., Serafeim, G. \& Krzus, M. P. (2011). Market interest in nonfinancial information. Journal of Applied Corporate Finance, 23(4), 113-127.

Eisenhardt, K. M. (1989). Agency theory: An assessment and review. Academy of management review, 14(1), 57-74.

Erlingsdóttir, G. \& Lindberg, K. (2005). Isomorphism, Isopraxism and IsonymismComplementary or Competing Processes? (No. 2005/4). http://www.lri.lu.se/pdf/wp/20054.pdf (accessed 19 April, 2017).

Flower, J. (2015). The international integrated reporting council: a story of failure. Critical Perspectives on Accounting, 27, 1-17.

Harding, T. (2012). How to establish a study association: Isomorphic pressures on new CSOs entering a neo-corporative adult education field in Sweden. Voluntas: International Journal of Voluntary and Nonprofit Organizations, 23(1), 182-203. 
Hedberg, C. J. \& Von Malmborg, F. (2003). The global reporting initiative and corporate sustainability reporting in Swedish companies. Corporate social responsibility and environmental management, 10(3), 153-164.

Hopwood, A. G. (2009). Accounting and the environment. Accounting, Organizations and Society, 34(3), 433-439.

Idowu, S. O., Capaldi, N. \& Zu, L. (2013). Encyclopedia of corporate social responsibility. Springer, Heidelberg, Germany.

Ioannou, I. \& Serafeim, G. (2012). What drives corporate social performance? The role of nation-level institutions. Journal of International Business Studies, 43(9), 834-864.

Ioannou, I. \& Serafeim, G. (2016). The consequences of mandatory corporate sustainability reporting: evidence from four countries. Harvard Business School Research Working Paper No. 11-100 https://papers.ssrn.com/soL3/papers.cfm?abstract_id=1799589 (accessed 14 April, 2017

IR (2013). International IR Framework, International Integrated Reporting Council. available at: $\quad$ http://integratedreporting.org/wp-content/uploads/2013/12/13-12-08-THEINTERNATIONAL-IR-FRAMEWORK-2-1.pdf (accessed 16 May, 2017).

IR (2017). Integrated Reporting. International Integrated Reporting Council https://integratedreporting.org/the-iirc-2/ (accessed 19 May, 2017).

Lozano, R. \& Huisingh, D. (2011). Inter-linking issues and dimensions in sustainability reporting. Journal of Cleaner Production, 19(2), 99-107.

Maniora, J. (2015). Is integrated reporting really the superior mechanism for the integration of ethics into the core business model? An empirical analysis. Journal of Business Ethics, 140(4), 755-786.

Maniora, J. (2017). Is integrated reporting really the superior mechanism for the integration of ethics into the core business model? An empirical analysis. Journal of Business Ethics, 140(4), 755-786.

Meyer, J. W., Boli, J., Thomas, G. M. \& Ramirez, F. O. (1997). World society and the nationstate. American Journal of sociology, 103(1), 144-181.

Muth, M. \& Donaldson, L. (1998). Stewardship theory and board structure: A contingency approach. Corporate Governance: An International Review, 6(1), 5-28.

Ness, K. E. \& Mirza, A. M. (1991). Corporate social disclosure: A note on a test of agency theory. The British Accounting Review, 23(3), 211-217.

Neu, D., Warsame, H. \& Pedwell, K. (1998). Managing public impressions: environmental disclosures in annual reports. Account. Org. Soc., 23, 265-282

O'Dwyer, B. (2003). Conceptions of corporate social responsibility: the nature of managerial capture. Accounting, Auditing \& Accountability Journal, 16(4), 523-557. 
Parent, M. M. \& Deephouse, D. L. (2007). A case study of stakeholder identification and prioritization by managers. Journal of business ethics, 75(1), 1-23.

Perego, P., Kennedy, S., \& Whiteman, G. (2016). A lot of icing but little cake? Taking integrated reporting forward. Journal of Cleaner Production, 136, 53-64.

PWC (2015) What do 1,300 CEOs worldwide say about today's business challenges and opportunities? http://www.pwc.com/gx/en/ceo-agenda/ceosurvey/2015.html (accessed 11 March, 2017)

Scott, W. R. (1995). Institutions and organizations (Vol. 2). Thousand Oaks, CA: Sage.

Simnett, R., \& Huggins, A. L. (2015). Integrated reporting and assurance: where can research add value?. Sustainability Accounting, Management and Policy Journal, 6(1), 29-53.

Stacchezzini, R., Melloni, G. \& Lai, A. (2016). Sustainability management and reporting: the role of integrated reporting for communicating corporate sustainability management. Journal of Cleaner Production, 136, 102-110.

Stubbs, W. \& Higgins, C. (2014). Integrated reporting and internal mechanisms of change. Accounting, Auditing \& Accountability Journal, 27(7), 1068-1089.

Suchman, M. C. (1995). Managing legitimacy: Strategic and institutional approaches. Academy of management review, 20(3), 571-610. 